\section{We need more randomised controlled trials in injury prevention}

\author{
Roderick J McClure
}

Results from randomised controlled trials make an important contribution to improvements in injury-related health. However, publication of findings from randomised controlled trials remains a rarity in the injury prevention literature.

Increasing the quantity of randomised controlled trials research need not reduce other types of injury prevention research activity. Highlighting the importance of publishing trials does not devalue the contribution of other designs. The paucity of trial evidence in injury prevention poses a risk to the advancement of the field. We need more randomised controlled trials in injury prevention.

In this issue of the journal, we publish five study protocols and the results of one completed study that illustrate how injury prevention researchers are using trial methodology to address important research questions.

The first protocol describes a randomised controlled trial designed to quantify the effect of a health education intervention on the safe-sleep knowledge, attitudes and practices of primary care givers of infant children. The second protocol is a cluster randomised controlled trial involving female soccer (football) players 14-18 years of age that aims to quantify the effect of a soccer-specific ankle brace on the incidence of acute lateral sprain of the ankle. The third protocol is a cluster stepped-wedge pragmatic trial of a wearable sensor device that alerts staff when patients engage in falls-risk activities. The study group in this protocol is inpatients aged over 65, and the study outcome is changes in fall rate. The fourth protocol is a cluster randomised controlled trial of an exercise-based warm-up or cooldown intervention involving male amateur club cricket teams of players between the ages of 14 and 40 years. The primary outcome measure is incidence of injury. The final protocol is a cluster randomised controlled trial designed to quantify the effect of child passenger restraint product information provided to parents by retailers on correct use 6 months after child restraint purchase. Also included in this issue is the report of a completed randomised controlled trial that quantified the effect of an education, brief

Correspondence to Dr Roderick J McClure, School of Rural Medicine, University of New England, Armidale, NSW 2351, Australia; rmcclure@une.edu.au intervention and take-home Naloxone intervention on subsequent acute opioid events among patients at risk of elevated overdose risk who present to emergency departments.

The simple list of five study protocols and a completed study illustrates several considerations facing injury prevention researchers when using trial methodology in injury prevention contexts.

The studies clearly illustrate that the randomised controlled trial design can be simply applied to injury intervention evaluation, without the need to adapt the logic or technical aspects of the classic medical-model randomised controlled trial. The protocols of the reported research, and the explanations in the manuscripts themselves, read very much as they would do had the interventions been medical treatments. While most readers would expect this, it is worth noting nonetheless as the world of injury prevention and the world of clinical care are some distance apart.

As shown by the included manuscripts, the trial methodology is applicable not only to injury prevention research without adaption but also across a range of injury prevention interventions. Within just these six studies, there is an evaluation of three education/behaviour change interventions, an exercise intervention, a warning device and a protective device.

A second point worth noting is that while the range of interventions is wide, other than the falls risk warning intervention, all other interventions described in the included manuscripts are either explicitly individual-level health education/ behaviour change interventions or interventions directly analogous to a typical medical treatment (eg, exercises and an ankle brace). The manuscripts in this issue do define a broad scope in injury prevention for the randomised controlled trial, but the limits of this scope mark out only a small part of the territory covered by the injury prevention field.

Informatively, only two of the six trials (both involving an intervention delivered by clinicians to individuals in a healthcare setting) randomised at the individual level. The other four studies chose to cluster randomise. The cluster approach may be particularly appropriate for injury prevention interventions, which are commonly delivered by third parties or through environmental change.

If we accept the premise that we need more randomised controlled trials in injury prevention, what can we conclude from a brief review of the trial manuscripts published in this issue? It is clear the randomised controlled trial works well for injury prevention intervention evaluation, within a circumscribed intervention type. We can confidently make much more use of the trial methodology within this range of interventions. There remains potential for injury prevention researchers to advance the technical aspects of the randomised controlled trial to make it more applicable to the types of interventions more commonly used by injury practitioners.

The real value of epidemiological designs lies in their scientific logic, not in the technical aspects of their application. There needs to be a consistency between the technical application and the design logic, and sufficient rigour in the application of the technical aspects to finesse threats to validity arising from such things as measurement error. However, as demonstrated by Haddon and colleagues as early as 1964 in their text Accident Research: Methods and Approaches, ${ }^{1}$ specific tailoring of the technical aspects of epidemiological designs can extend their applicability beyond the intended medical uses for which the epidemiological study designs were first described.

Yes, we need more randomised controlled trials in injury prevention, and we need injury researchers to do more to develop the randomised controlled trial design so that it becomes more realistically usable for the full range of interventions injury prevention researchers need to evaluate.

Funding The authors have not declared a specific grant for this research from any funding agency in the public, commercial or not-for-profit sectors.

Competing interests None declared.

Patient consent for publication Not required.

Provenance and peer review Not commissioned; internally peer reviewed.

(C) Author(s) (or their employer(s)) 2019. No commercial re-use. See rights and permissions. Published by BMJ.

$$
\text { Check for updates }
$$

To cite McClure RJ. Inj Prev 2019;25:145. Published Online First 16 April 2019

Inj Prev 2019;25:145.

doi:10.1136/injuryprev-2019-043253

\section{REFERENCE}

1 Haddon W, Suchman EA, Klein D. Accident research: methods and approaches. New York, NY: Harper and Row, 1964. 